\title{
Ultrasound and ionic liquid-enhanced extractive desulfurization of diesel
}

\author{
Karma Zuraiqi, Paul Nancarrow, * Hussain Ahmed \\ Department of Chemical Engineering \\ American University of Sharjah \\ United Arab Emirates \\ pnancarrow@aus.edu
}

\begin{abstract}
The current desulfurization technology, hydrodesulfurization (HDS), is energy intensive, uses large quantities of hydrogen, and is ineffective at removing some sulfur compounds. Ionic liquids have been recently shown to perform well as extraction solvents for the removal of sulfur from diesel. However, a major limitation towards their industrial use is the low mass transfer rates that result from their relatively high viscosities. This study investigates the use of ultrasound to overcome this problem. The ionic liquid, 1-ethyl-3methylimidazolium acetate $\left(\left[\mathrm{C}_{2} \mathrm{mim}\right]\left[\mathrm{CH}_{3} \mathrm{COO}\right]\right)$, was used to desulfurize model diesel consisting of dibenzothiophene in hexadecane, in the absence and presence of ultrasound. It was found that sonification can greatly enhance the rate of mass transfer of DBT from diesel to the IL, resulting in a $57 \%$ sulfur removal for a $\mathbf{7 5 \%}$ decrease in extraction time for batch studies, which results in a reduction in the number of equilibrium stages necessary for a continuous extraction process.
\end{abstract}

Keywords—ionic liquid; ultrasound; desulfurization; diesel

\section{INTRODUCTION}

Today diesel fuel plays a crucial role in shaping our economies worldwide. It is used in transportation, industrialization and power generation, for example [1]. Diesel consumption is directly related to global economy, making its optimization a universally central issue. However, the widespread use of diesel has also associated with atmospheric pollution, environmental degradation and serious health issues. In recent years, the need for improved pollution control systems is becoming more popular due to increasing environmental awareness and increase in stringent regulations regarding fuel oils quality and specifications. Sulfur compounds present in diesel turn to SOX derivatives upon combustion, which have major detrimental environmental impacts. These compounds cause acid rain, ozone depletion, and jeopardize living organisms. Acid rain can lower soil $\mathrm{pH}$, affect agriculture and cause deforestation, change climate, endanger marine life, and corrode or weaken materials. Sulfur dioxide, if inhaled, can inflict serious health problems. Health problems associated with sulfur dioxide generally involve the respiratory system. Current regulations call for ultra-clean fuel, with sulfur content as low as 10 ppm in many countries [2].

The current industrial desulfurization technology, HDS is a costly, capital and energy intensive process requiring large quantities of explosive hydrogen, and is not highly effective at removing sterically hindered organosulfur compounds such as DBT and its derivatives, which are common in raw diesel. The problems with the current technology have brought about the need for innovative cost effective and safer alternative solutions.

Owing to the negligible vapor pressures of ILs and their effectiveness in the removal of DBT, ILs make for a very attractive solvent choice in the extractive desulfurization of diesel fuel [3]. However, the high viscosity of these liquids, which results in reduced mass transfer rates can be considered a significant disadvantage. Hence, desulfurization can be aided by auxiliary techniques that could enhance mass transfer.

The ability of US to agitate, generate cavitation, cause localized increases in temperatures, and attenuate solvent viscosity [4] are the reasons behind the selection of irradiation in this study to facilitate the desulfurization process and overcome the mass transfer limitations in IL extraction. The effects of US on the mass transfer rate and extraction process design in the desulfurization of diesel are thus investigated in this paper.

\section{EXPERIMENTAL}

\section{A. Chemicals and Materials}

Dibenzothiophene and n-hexadecane, were supplied by the Sigma-Aldrich Chemical Company with cited purities of $98 \%$, and $99 \%$ respectively. $\left[\mathrm{C}_{2} \mathrm{mim}\right]\left[\mathrm{CH}_{3} \mathrm{COO}\right]$ was supplied by IOLITEC Ionic Liquids Technologies with cited purity of $95 \%$. Supplied chemicals were used without any further purification.

\section{B. Desulfurization Experiment}

The initial sulfur content of model diesel was recorded before equal volumes of model diesel and IL were placed into the mixing vessel. The system was subjected to sonification in a Bransonic $351040 \mathrm{~Hz}$ ultrasonic batch at room temperature for a fixed time duration. Samples of the diesel phase were extracted at fixed time intervals and sulfur content was determined using an Ametek X-ray fluorescence (XRF) spectrometer. To ensure complete phase separation prior to analysis, samples were subjected to centrifugation for several minutes and then immediately tested using XRF. An identical system without sonification was set up as a control to compare 
the rate of desulfurization with, and in the absence of ultrasound, as illustrated in Fig. 1.

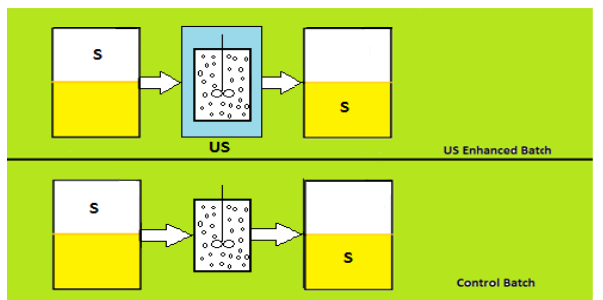

Fig. 1 Experimental setup for desulfurization with and without sonification.

\section{RESULTS AND DISCUSSION}

\section{A. Effect of Ultrasound on Desulfurization}

By investigating mass transfer rate in two batch desulfurization systems, one batch subjected to ultrasound irradiation while maintaining the other batch as a control, the influence of ultrasound on the desulfurization rate was studied. Both systems were operated under the same conditions: room temperature at $22{ }^{\circ} \mathrm{C}$, model diesel to IL ratio of $1: 1$, same vessel size. In the first experiment, no agitation was used, so that the interfacial boundary was clearly defined.

As evident from Fig. 2, the rate of desulfurization in the system involving sonification was notably higher than that without sonification, indicating the potential for using ultrasound to enhance the extraction process.

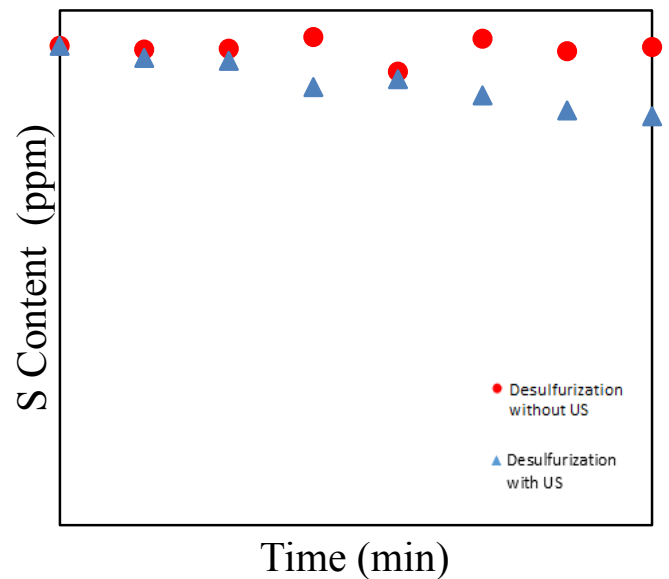

Fig. 2. Change in sulfur content of model diesel as a function of time for non-agitated batch extraction with $\left[\mathrm{C}_{2} \mathrm{mim}\right]\left[\mathrm{CH}_{3} \mathrm{COO}\right]$ in the presence of sonification (blue) and without sonification (red) in a $31 \mathrm{~mm}$ diameter vessel.

Results illustrated in Fig. 2 indicate that while the system is undergoing a steady desulfurization over time, changes in sulfur content for the system not subjected to ultrasound are almost negligible. This illustrates a very low rate of mass transfer in the IL phase and, hence, the need for a mass transfer enhancing method. In contrast, in the sonicated system, sulfur content is clearly decreasing over time.

Fig. 3 illustrates the significant improvement in desulfurization achieved through sonification in a larger extraction vessel (67 mm diameter). Both systems show faster sulfur removal over time compared with the $31 \mathrm{~mm}$ diameter extraction vessel; this is attributed to to the larger interfacial area. Furthermore, the sonicated process has removed approximately three times more sulfur compared with the nonsonicated process after 180 minutes.

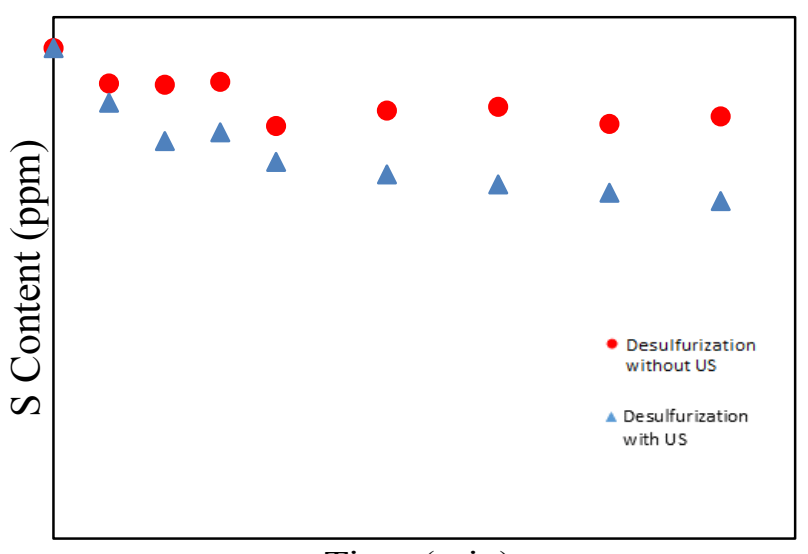

Time (min)

Fig. 3 Change in sulfur content of model diesel as a function of time for a non-agitated batch extraction using $\left[\mathrm{C}_{2} \mathrm{mim}\right]\left[\mathrm{CH}_{3} \mathrm{COO}\right]$ in the presence of sonification (blue - $\Delta$ ) and without sonification (red - o) in a $67 \mathrm{~mm}$ diameter vessel.

\section{B. Effect of Agitation}

As shown in the previous section, the interfacial area between the liquid phases is a key parameter affecting mass transfer rate. A common method to increase interfacial area in extraction systems is mechanical agitation. Therefore, this section addresses the effect of agitation on the rate of desulfurization of diesel.

To investigate the use of mechanical agitation on the desulfurization rate, in the presence and absence of ultrasound, experiment was repeated under identical conditions except that an impeller was used to provide mixing at $400 \mathrm{rpm}$ (Fig. 4).

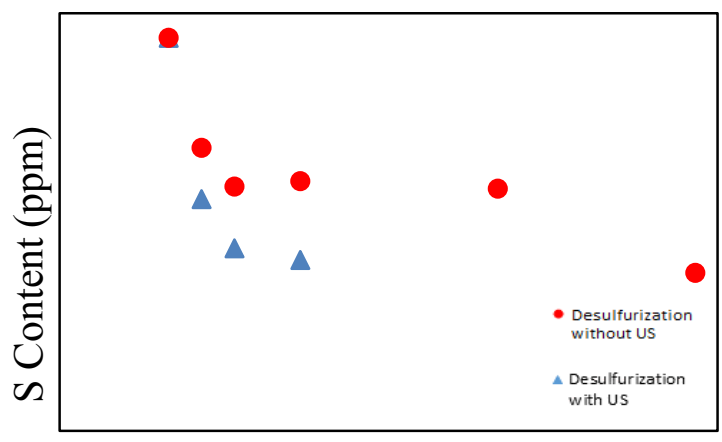

Time (s)

Fig. 4 Change in sulfur content of model diesel as a function of time for the batch extraction with $\left[\mathrm{C}_{2} \mathrm{mim}\right]\left[\mathrm{CH}_{3} \mathrm{COO}\right]$ with agitation at $400 \mathrm{rpm}$ in the presence of sonification (blue - $\Delta$ ) and without sonification (red - o) in a 67 $\mathrm{mm}$ diameter vessel.

With the introduction of agitation, the system reached equilibrium at a much faster rate, i.e. reaching an equilibrium sulfur removal of $\sim 60 \%$ in seconds, rather than hours. However, as shown in Fig. 4, the use of ultrasound can significantly enhance the mass transfer rate even when mechanical agitation is used. Consequently, these results 
verify that ultrasound can be potentially integrated into extractive desulfurization involving IL as extractive solvents, to significantly accelerate desulfurization rates.

The benefit of agitation is further illustrated by Fig. 5, which compares the agitated with non-agitated system for the US assisted desulfurization of model diesel using IL. As expected, desulfurization is greatly enhanced by the agitation to the system.

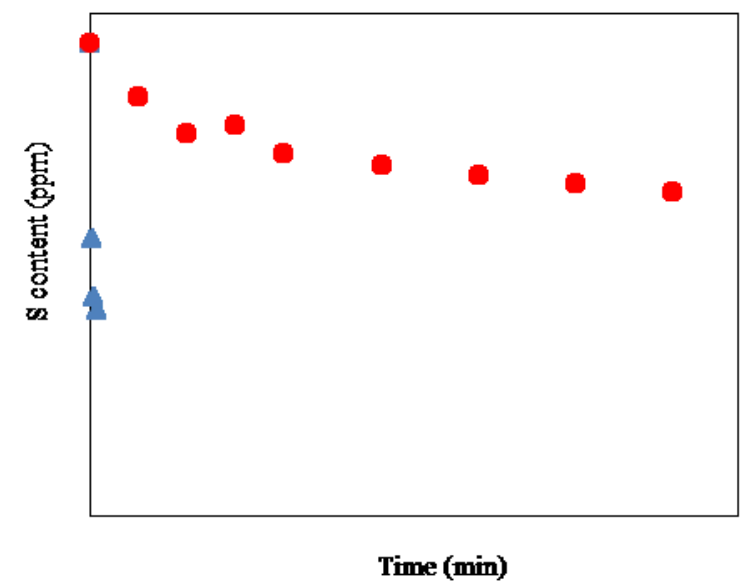

Fig. 5 Effect of agitation on desulfurization for batch extraction subjected to sonification, for an agitated (blue - $\Delta$ ) and a non-agitated (red - o) system, in a $67 \mathrm{~mm}$ diameter vessel.

\section{Effect of Vessel Size}

Vessel size is another system parameter that can affect the interfacial area between the two liquid phases. Fig. 6 illustrates the effect of vessel diameter on the extractive desulfurization of diesel using $\left[\mathrm{C}_{2} \mathrm{mim}\right]\left[\mathrm{CH}_{3} \mathrm{COO}\right]$.

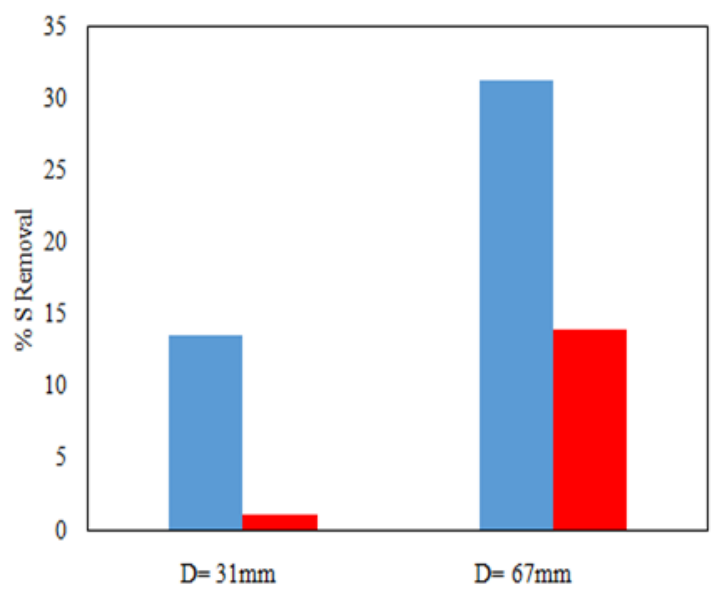

Fig. 6 Effect of extractor vessel diameter on the \% sulfur removal for non-agitated batch extraction, in the presence of sonification (blue) and without sonification (red) in $31 \mathrm{~mm}$ and $67 \mathrm{~mm}$ diameter vessels for $180 \mathrm{~min}$ extraction time.

For a fixed desulfurization period, the employment of a larger vessel diameter shows an increase in sulfur removal of approximately $18 \%$ and $13 \%$ in the presence and absence of sonification respectively. For the non-agitated system, interfacial area is simply the cross-sectional area of the vessel, which increases with vessel diameter. Therefore, the results obtained are compliant with expectations.

\section{Extraction Process Design}

\section{A. Effect of Ultrasound on Initial Mass Transfer Rate}

Since ultrasound has significant potential for the improvement of mass transfer in IL extraction processes, quantification of the mass transfer rate is necessary for the adequate design and scale-up of process equipment.

The initial mass transfer rate can be acquired from the slope of the tangent line formed for the region of the curve at the early stages of desulfurization, as illustrated in Fig. 7.

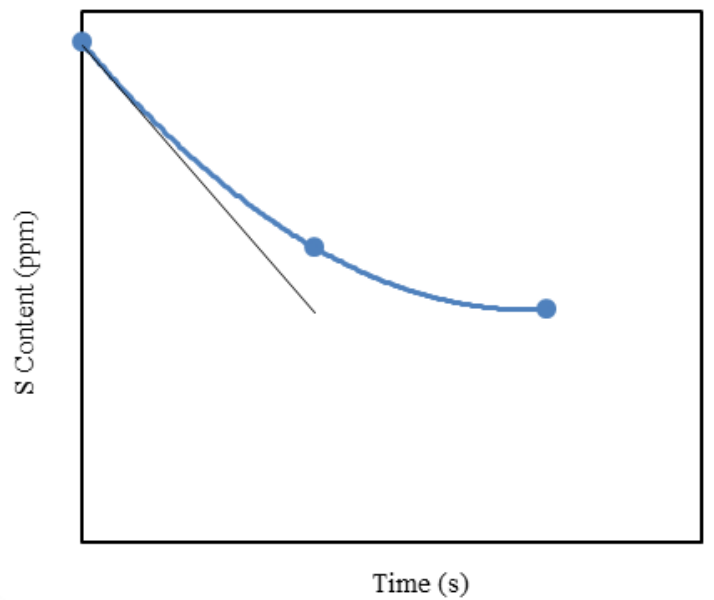

Fig. 7 Schematic representation of the generation of initial mass transfer rate for the desulfurization experiment.

Calculated initial mass transfer rates for the desulfurization of agitated batch experiments mixed at $400 \mathrm{rpm}$ at room temperature are compared to show the effect of ultrasound. As evident from Table I, the initial mass transfer rate and volumetric mass transfer coefficient, KA, are almost doubled through the use of ultrasound, as excepted.

TABLE I. INITIAL MASS TRANSFER RATE FOR THE EXTRACTION OF DBT FROM HEXADECANE IN THE PRESENCE AND ABSENCE OF ULTRASOUND

\begin{tabular}{l|cc} 
& $\begin{array}{c}\text { Ultrasound } \\
\text { Assisted }\end{array}$ & No Ultrasound \\
\hline $\begin{array}{l}\text { Initial Mass Transfer } \\
\text { Rate }(\mathrm{ppm} / \mathrm{s})\end{array}$ & 117 & 65 \\
$\mathrm{KAx} 10^{5}(1 / \mathrm{s})$ & 1.78 & 0.99
\end{tabular}

Although volumetric mass transfer coefficients can be derived from the initial mass transfer rates, the use of an interphase mass transfer model that can adequately explain the mass transfer in batch extraction can provide more accurate representation.

\section{B. Mass Transfer Model}

In order to quantify the effect of US on the desulfurization process, and to calculate the mass transfer coefficient for sonicated systems as well as systems not subjected to US, mass transfer rates were modeled. Equation (1) describes the mass transfer in the batch extraction system: 


$$
-V_{C 16} \frac{d C_{C 16}}{d t}=K A_{i}\left(C_{C 16}-\left(\frac{V_{C 16}}{D_{r} V_{I L}}\right)\left(C_{C 16}^{0}-C_{C 16}\right)\right)
$$

where $\mathrm{C}_{\mathrm{C} 16}$ is the sulfur content in the hexadecane, $\mathrm{C}_{\mathrm{C} 16}^{0}$ is the initial sulfur content at the initial time, $\mathrm{V}_{\mathrm{C} 16}$ is the hexadecane volume, $\mathrm{V}_{\mathrm{IL}}$ is the IL volume, $\mathrm{A}_{\mathrm{i}}$ is the interface area, $D_{r}$ is the distribution coefficient, and $K$ is the mass transfer coefficient of the system. Since the volume of the IL is equal to the volume of the hexadecane, i.e. $\mathrm{V}_{\mathrm{C} 16}=\mathrm{V}_{\mathrm{IL}}$, the equation can be simplified.

By separation of the variables, the solution to the differential equation was obtained which was then fitted to the experimental data using the nlinfit toolbox in MATLAB. The toolbox utilizes the free variable available in the power of the exponential to fit the data for the system.

$$
C_{C 16}=C_{C 16}^{0}\left(\left(\alpha-\frac{1}{\alpha}\right)+\frac{e^{-\alpha \beta t}}{\alpha}\right)
$$

where,

$$
\alpha=1+\frac{1}{D_{r}}
$$

and

$$
\beta=\frac{K A_{i}}{V_{C 16}}
$$

From analysis of the fitted parameters, the volumetric mass transfer coefficient, KA, was obtained for each system. This is a quantitative measure of the desulfurization rate in the extraction process and can be used to compare the various systems. This model was plotted on the same axes as the experimental data in Figs 8, 9, and 10, to show the performance of the model in representing the mass transfer behavior of the system.

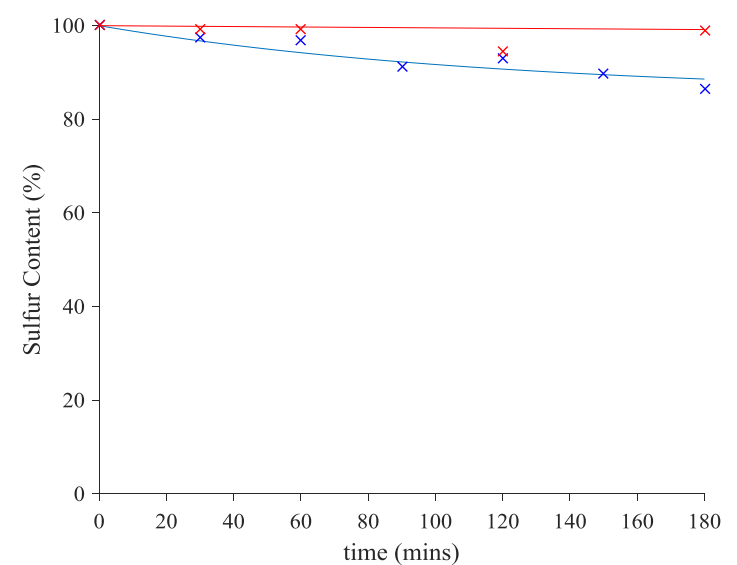

Fig. 8 Change in sulfur content of model diesel as a function of time using the modeled mass transfer rate for non-agitated batch extraction with $\left[\mathrm{C}_{2} \mathrm{mim}\right]\left[\mathrm{CH}_{3} \mathrm{COO}\right]$ in the presence of sonification (blue) and without sonification (red) in a $31 \mathrm{~mm}$ diameter vessel.

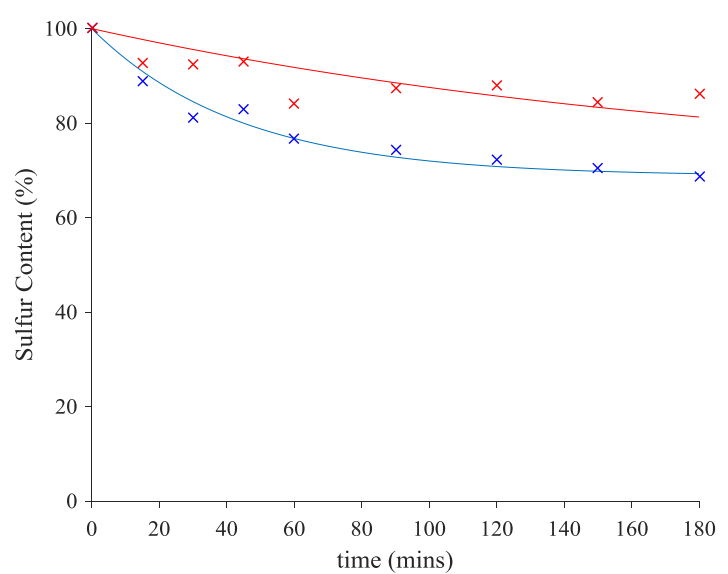

Fig. 9 Change in sulfur content of model diesel as a function of time using the modeled mass transfer rate for non-agitated batch extraction with $\left[\mathrm{C}_{2} \mathrm{mim}\right]\left[\mathrm{CH}_{3} \mathrm{COO}\right]$ in the presence of sonification (blue) and without sonification (red) in a $67 \mathrm{~mm}$ diameter vessel.

Volumetric mass transfer coefficients derived from Figs. 6 and 7 are summarized in Table II for non-agitated batch extraction.

TABLE II. EFFECT OF ULTRASOUND ON VOLUMETRIC MASS TRANSFER COEFFICIENT FOR TWO VESSEL SIZES

\begin{tabular}{c|cc} 
& $67 \mathrm{~mm}\left(\mathrm{KA} \times 10^{5}(1 / \mathrm{s})\right)$ & $31 \mathrm{~mm}\left(\mathrm{KAx} 10^{5}(1 / \mathrm{s})\right)$ \\
\hline $\begin{array}{c}\text { Ultrasound } \\
\text { Assisted } \\
\text { No }\end{array}$ & 38.1 & 6.77 \\
Ultrasound & 8.71 & 0.26
\end{tabular}

Table II shows that the volumetric mass transfer coefficient for the non-agitated desulfurization system increases with the increase in the extractor vessel diameter, as well as the use of ultrasound.

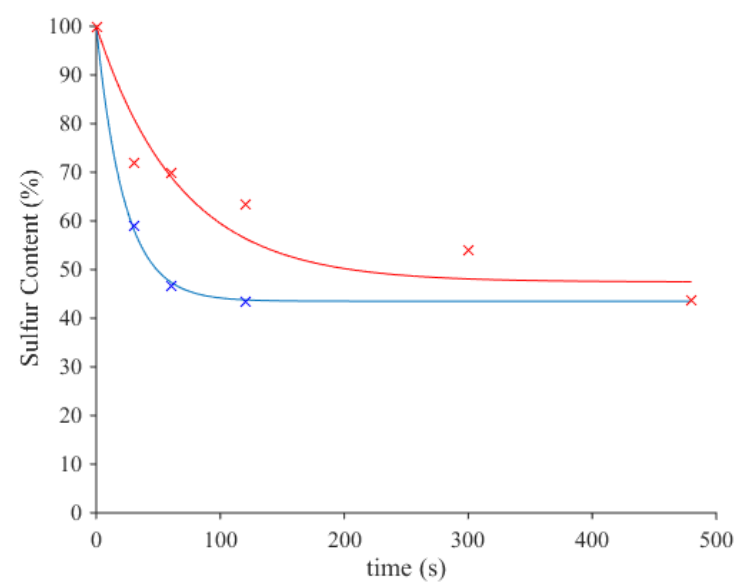

Fig. 10 Change in sulfur content of model diesel as a function of time using the modeled mass transfer rate for batch extraction agitated at $400 \mathrm{rpm}$ with $[\mathrm{C} 2 \mathrm{mim}][\mathrm{CH} 3 \mathrm{COO}]$ in the presence of sonification (blue) and without sonification (red) in a $67 \mathrm{~mm}$ diameter vessel

The enhancement in rate of sulfur removal due to sonification can be clearly observed in Fig. 10, showing that the system subjected to ultrasound reaches the equilibrium sulfur concentration faster than the system without ultrasound. Moreover, using the model illustrated in Fig. 8 the volumetric 
mass transfer coefficients are calculated for comparison between the irradiated system and the system without ultrasound.

TABLE III. EFFECT OF ULTRASOUND ON VOLUMETRIC MASS TRANSFER COEFFICIENT FOR AN AGITATED BATCH EXTRACTION

\begin{tabular}{c|c} 
& $K A \times 10^{2}(1 / s)$ \\
\hline Analytic & 2.87 \\
No Ultrasound & 2.80 \\
Ultrasound & 8.43 \\
Assisted &
\end{tabular}

Analytic solution values presented in Table III are used as a reference to which calculated volumetric mass transfer coefficient values for the agitated system are compared. The analytic values are determined by calculating the diffusivity using the Wilke-Chang correlation, $D_{W C}$, and diffusivity using the Schiebel correlation, $D_{\text {Sch, }}$ as summarized in equations (511) $[5]$

$$
\begin{gathered}
D_{W C}=\frac{7.4 \times 10^{-8}\left(\varnothing M w t_{I L}\right)^{0.5} T}{\mu_{I L} V_{D B T}^{0.6}} \\
D_{S c h}=8.2 \times 10^{-8}\left(1+\left(\frac{3 V_{C_{16}}}{V_{D B T}}\right)^{0.66}\right) \frac{T}{\mu_{C_{16}} V_{D B T}^{0.33}} \\
R e=\frac{N d_{i} \rho}{\mu} \\
S c=\frac{\mu}{\rho D_{W C / S c h}} \\
S h=0.664 R e^{0.5} S c^{\frac{1}{3}} \\
S h=\frac{k_{I L / C_{16}} d_{i}}{D_{W C / S c h}} \\
\frac{1}{K}=\frac{1}{k_{C_{16}}}+\frac{1}{d_{r} k_{I L}}
\end{gathered}
$$

Where Sc, Sh, and Re are the Schmidt, Sherwood, and Reynolds numbers respectively. Other parameters include $M w t_{I L}$, molecular weight of the IL, $T$, system temperature, $\mu$, fluid viscosity, $\rho$, fluid density, $d_{i}$, impeller diameter, $d_{r}$, distribution coefficient, and $N$ which represent the molecular weight of the IL, system temperature, fluid viscosity, fluid density, impeller diameter, distribution coefficient, and impeller speed respectively. Here for the IL/oil system, the association factor, $\phi$, is assumed to equal to 1.0 due to IL characteristics. It can be observed from equations (5-11) that $\mathrm{K}$ values can be affected by system diffusivities and solution properties.

Mass transfer as per Tables II and III has been consistently enhanced in the presence of sonification, with results shown in Table III showing a KA value for the ultrasound assisted system that is more than 3 times the KA value for the system not subjected to ultrasound. Moreover, vessel size and agitation further improved the mass transfer coefficient. Therefore, the increase in the volumetric mass transfer coefficient, and the enlargement of the interfacial area due to sonification result in the acceleration of desulfurization rates and total sulfur removal. It is well established that ultrasound can enhance extraction rates due to either increases in mass transfer coefficient and effective diffusivity [6], or by decreasing dispersed droplets size and increasing interfacial area [7]. Observed overall enhancement to the desulfurization of diesel using $\left[\mathrm{C}_{2} \mathrm{mim}\right]\left[\mathrm{CH}_{3} \mathrm{COO}\right]$, brought about by sonification, can be attributed to a combination of both factors.

\section{CONCLUSION}

As extraction solvents, ILs show great extraction potential in desulfurizing diesel oil. However, the environmental compatibility of these liquids is faced by operation difficulty due to their high viscosity. Lower extraction rates due to the high viscosity characteristic, nonetheless, can be resolved by applying techniques of mass transfer enhancement. This paper proposes the use of ultrasound to accelerate desulfurization rates.

Results obtained indicate significant mass transfer improvement by sonification, showing a 57\% sulfur removal for a $75 \%$ reduction in residence time for the agitated batch extraction upon subjection to sonification. Furthermore, volumetric mass transfer coefficients obtained for the ultrasound assisted extraction are consistently greatly larger than those for the non-ultrasound system. The increase in volumetric mass transfer coefficient and interfacial areas displayed by the system subjected to ultrasound result in an enhancement to the volumetric mass transfer rate.

\section{References}

[1] US Energy Information Administration. https://www.eia.gov/energyexplained/index.cfm?page=diesel_use

[2] L.G. Chestnut, D. M. Mills, "A fresh look at the benefits and costs of the US acid rain program,” J. Environ. Manage., vol. 77, pp. 252-266, 2005.

[3] P. Nancarrow, N. Mustafa, A. Shahid, V. Varughese, U. Zaffar, R. Ahmed, N. Akther, H. Ahmed, I. AlZubaidy, S. Hasan, Y. Elsayed, Z. Sara, "Technical evaluation of ionic liquid-extractive processing of ultra low sulfur diesel fuel," Ind. Eng. Chem. Res., vol. 54, pp. 10843-10853, 2015 .

[4] B. Zisu, M. Schleyer, and J. Chandrapala, "Application of ultrasound to reduce viscosity and control the rate of age thickening of concentrated skim milk," Int. Dairy J., vol. 31, no. 1, pp. 41-43, 2013.

[5] A. R. Ferreira et al., "Removal of thiols from model jet-fuel streams assisted by ionic liquid membrane extraction," Chemical Engineering Journal, vol. 256, pp. 144-154, 2014.

[6] L. H. Thompson and L. K. Doraiswamy, "Sonochemistry: Science and Engineering," Industrial \& Engineering Chemistry Research, vol. 38, no. 4, pp. 1215-1249, 1999.

[7] J. Huang, Y. Liu, Z. Song, Q. Jin, and X. Wang, "Kinetic study on the effect of ultrasound on lipase-catalyzed hydrolysis of soy oil: Study of the interfacial area and the initial rates," Ultrasonics sonochemistry, vol. 17 , no. 3 , pp. $521-5,2010$. 